\title{
Functionele Transcraniële Doppler voor taallateralisatie
}

Functionele Transcraniële Doppler is een goede voorspeller voor typische, linkszijdige taallateralisatie en vormt daarmee een aantrekkelijk alternatief voor kostbare functionele MRI-onderzoeken en de invasieve Wada-test. In deze bijdrage een verslag van een onderzoek bij epilepsiechirurgiekandidaten voor wie met behulp van functionele Transcraniële Doppler werd vastgesteld welke hemisfeer taaldominant was.

De dominante hemisfeer is de hersenhelft waarin taalfunctie is gelokaliseerd. Bij de meeste mensen is dat aan de linkerkant. We spreken dan van een typische taallateralisatie. Dat geldt zowel voor rechts- als linkshandige mensen, maar bij rechtshandigen is de kans op een typische taallateralisatie groter dan bij linkshandigen. Bij patiënten met epilepsie is er vaker sprake van atypische taallateralisatie en is de relatie tussen rechtshandigheid en typische taallateralisatie minder sterk. Hier kan dus niet zonder meer worden aangenomen dat rechtshandigheid voorspellend is voor een typische taallateralisatie, met de taalfunctie in de linkerhemisfeer.

\section{De Wada-test}

Wanneer patiënten met medicatieresistente epilepsie een hersenoperatie ondergaan om de aanvallen te laten stoppen, mag het hersengebied dat wordt verwijderd geen taalfunctie bevatten. Voordat de patiënt een operatie ondergaat is het belangrijk om te weten of de te opereren hersenhelft taalfunctie bevat. De gouden standaard voor taallateralisatie is de Wada-test. Bij deze test wordt tijdens een cerebrale angiografie een kortwerkend anestheticum in de halsslagader geïnjecteerd, zodat de functies van de contralaterale hemisfeer kunnen worden getest. Als er na injectie van het anestheticum in de rechter halsslagader geen afasie ontstaat, dan kan worden geconcludeerd dat de taalfunctie volledig afhankelijk is van de linker hersenhelft. De Wadatest is een invasief onderzoek dat ziekenhuisopname vergt waar meerdere disciplines bij betrokken zijn (radioloog, neuroloog, neuropsycholoog) met een (klein) risico op het ontstaan van complicaties, zoals cerebrale ischemie of een slagaderlijke bloeding in het bovenbeen.

\section{Wat is het alternatief?}

Een veelgebruikt alternatief voor de Wada-test is functionele MRI (fMRI). Bij dat onderzoek wordt een hersenscan gemaakt terwijl de patiënt taaltaken uitvoert (bijvoorbeeld werkwoorden bedenken) wanneer hij of zij in de scanner ligt. Bij een typische taallateralisatie is er sprake van acti- vatie van gebieden links-frontaal (Broca) en links-temporaal (Wernicke). Voor typische taallateralisatie werd een concordantie gevonden in 9r\% en voor atypische taallateralisatie $71 \%$ (Rutten, 2002). Voor het slagen van fMRI is het belangrijk dat de patiënt de instructies goed begrijpt en gedurende de scan stil blijft liggen. Dit kan een probleem zijn voor kinderen of mensen met een verstandelijke beperking.

Bij functioneel Transcranieel Doppler onderzoek (fTCD) worden de stroomsnelheden van de twee grote hersenslagaders (arteria cerebri media links en rechts) gemeten tijdens het uitvoeren van een taaltaak (zoals woorden in stilte opsommen). De hersengebieden die actief worden bij taaltaken vragen meer bloed en als gevolg daarvan neemt de bloedstroom in de verzorgende hersenslagader toe. Dus als fTCD een grotere toename meet in de arteria cerebri media links ten opzichte van rechts ten tijde van het uitvoeren van taaltaken, kan een typische taallateralisatie worden verondersteld. Eerder onderzoek bij patiënten met een temporaalkwabepilepsie toont een goede correlatie tussen de Wada-test en fTCD met een correlatiecoëfficient van $78 \%$ voor de lateralisatie-indices (Knake, 2003). Er zijn geen vergelijkende onderzoeken van fTCD met fMRI bij patiënten met epilepsie.

Ten opzichte van de Wada-test en fMRI heeft fTCD een aantal praktische voordelen. Het onderzoek kan poliklinisch worden uitgevoerd en vergt weinig personeel. De patiënt hoeft ook niet stil te liggen en de meetopstelling is verplaatsbaar. Daarnaast is fTCD relatief goedkoop.

\section{Het onderzoek}

Er werd een vergelijkend onderzoek uitgevoerd bij 36 patiënten (leeftijd 9-55 jaar) die kandidaat waren voor een operatie. De patiënten kregen zowel een fTCD- als een fMRI-onderzoek. Voor het fTCD-onderzoek worden twee transducer probes geplaatst op het temporale botvenster, zodat met een Doppler-apparaat de bloedstroom van de 
arteria cerebri media beiderzijds gemeten kan worden. De patiënt zit achter een computerscherm en voert taaltaken uit waarbij periodes van rust (30 seconden)

worden afgewisseld met periodes waarin hij of zij in stilte woorden genereert (I5 seconden). De woorden moeten beginnen met de letter die gedurende tweeëneenhalve seconden zichtbaar is op het computerscherm direct na de rustperiode. Na het in stilte generen van woorden zegt de patiënt een aantal van de woorden hardop. Een dergelijke trial duurt een minuut. Er worden twintig trials uitgevoerd met telkens een andere letter. Aan het begin van de trial wordt tijdens de rustperiode een blauw scherm getoond en wordt aan de patiënt gevraagd te denken aan de sterrenhemel. Vervolgens wordt het verschil in bloedstroom van beide hemisferen gedurende de taaltaak uitgedrukt als de lateralisatie index met bijbehorende standaarddeviatie (Deppe et al, 2004). Een positieve index betekent dat de linker hemisfeer een grotere bloedstroom heeft en een negatieve index betekent dat de rechter hemisfeer een grotere bloedstroom heeft tijdens het uitvoeren van de taaltaken. Een voorbeeld hiervan is weergegeven in figuur I. Typische taallateralisatie voor fTCD is gedefinieerd als een positieve lateralisatie index die groter is dan tweemaal de standaarddeviatie.

Vervolgens werden de resultaten van $\mathrm{fTCD}$ vergeleken met de resultaten van het fMRI-onderzoek, dat volgens standaard klinische procedures werd uitgevoerd. fMRI-activatie van Broca en Wernicke links wordt beschouwd als typische taallateralisatie. Bilaterale of rechtszijdige activatie wordt beschouwd als atypisch. Van de patiënten met een typische (linkszijdige) taallateralisatie volgens het fMRI-onderzoek $(n=30)$ vertoonden 25 een overeenkomend resultaat van het fTCD-onderzoek.

Er zijn dus vijf patiënten met typische taallateralisatie vol- gens fMRI die een atypische taallateralisatie hebben met fTCD. Alle patiënten met een atypische taallateralisatie volgens het fMRI-onderzoek $(n=6)$ vertoonden ook een atypische taallateralisatie als resultaat van het fTCD-onderzoek. Hieruit kan worden afgeleid dat voor typische taallateralisatie fTCD een sensitiviteit heeft van $25 / 30=83 \%$, een positief voorspellende waarde heeft van $25 / 25=100 \%$ en negatief voorspellende waarde van $5 / \mathrm{II}=45 \%$.

\section{Discussie}

De resultaten van fTCD voor taallateralisatie in deze populatie van kandidaten voor epilepsiechirurgie zijn veelbelovend. In dit kleine cohort is fTCD een goede voorspeller gebleken voor een typische (linkszijdige) taallateralisatie. Voor de klinische praktijk zou dat kunnen betekenen dat, als de vraag zich beperkt tot het vaststellen van taallateralisatie, er een keuze gemaakt kan worden tussen fMRI en fTCD. Als fTCD typische taallateralisatie toont dient bij een operatie in de linker hemisfeer rekening te worden gehouden met de aanwezigheid van taalfunctie en zullen er voorzorgsmaatregelen getroffen worden om de taalgebieden niet te beschadigen. Dit kan door testen te doen met elektrodegrids die direct op de hersenschors liggen (subdurale grids) of de hersenoperatie wakker uit te voeren met continu testen van de taalfunctie. Wanneer fTCD atypische taallateralisatie laat zien lijkt het verstandig om dit te bevestigen met een of meer andere onderzoeken zoals fMRI en de Wada-test. Opgemerkt dient te worden dat bij sommige patiënten die in aanmerking komen voor een hersenoperatie ook de geheugenfuncties per hersenhelft dienen te worden onderzocht. FTCD is hier niet geschikt voor en vooralsnog kan dat alleen betrouwbaar worden gedaan met de Wada-test. De toekomst zal moeten uitwijzen in welke gevallen fTCD het fMRI-onderzoek kan vervangen voor taallateralisatie waarbij rekening

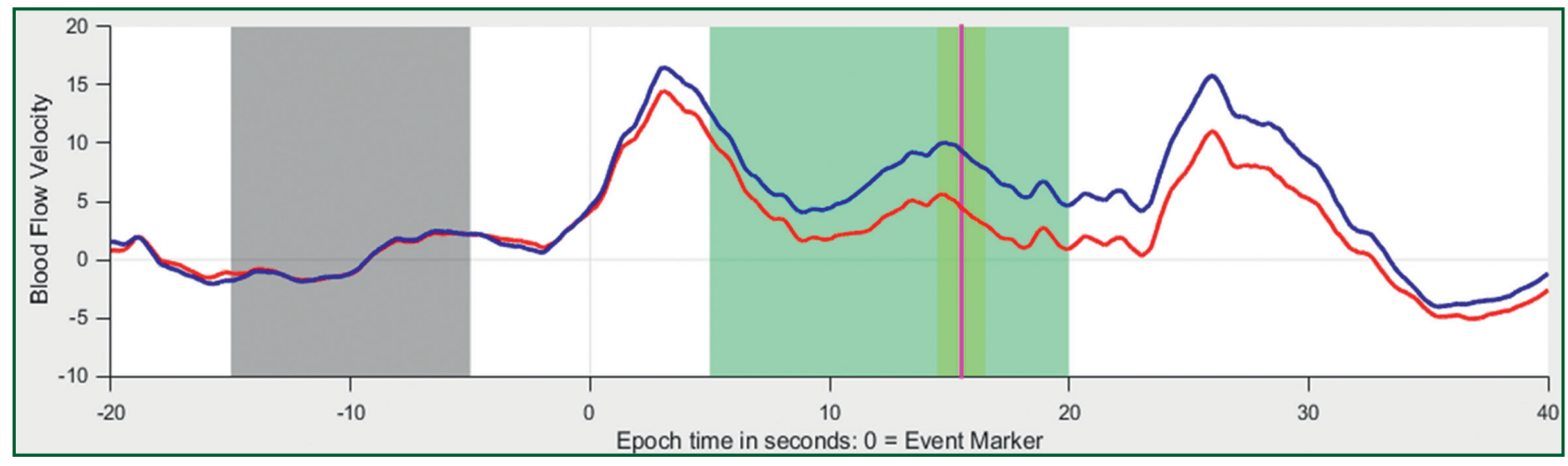

Figuur 1 Gemiddelde genormaliseerde bloedstroom van de arteria cerebri media rechts (rood) en links (blauw) tijdens de trials waarbij rust wordt afgewisseld met uitvoeren van een taaltaak. $\mathrm{T}=0$ sec is het moment waarop de letter op het beeldscherm wordt aangeboden. In de periode ervoor [ $-20,0 \mathrm{sec}]$ is er stilte waarbij de periode van $[-15,-5 \mathrm{sec}]$ gedefinieerd is als 'baseline' (grijs). Het interval [5, $20 \mathrm{sec}]$ is gedefeniëerd als period of interest (groen) en hierin genereert de patiënt in stilte de woorden. De software bepaalt automatisch de maximale lateralisatie-index (inclusief standaardafwijking) met bijbehorende latentie. De analyse bij deze patiënt toont op $\mathrm{T}=15,51$ sec een positieve lateralisatie index van 4.74 (standaarddeviatie 0.46) wijzend op typische (linkszijdige) taallateralisatie. 
gehouden kan worden met meer variabelen zoals rechtsof linkshandigheid, aanvalssemiologie en het vermoedelijke focus van de aanvallen. Daarnaast zal moeten blijken of fTCD in staat is om lateralisatie van andere cognitieve domeinen (bijvoorbeeld geheugen) in kaart te brengen.

\section{Referenties}

Deppe M, Ringelstein EB, Knecht S (2004) The investigation of functional brain lateralization by transcranial Doppler sonography. Neuroimage Mar;21(3):1124-46.
Knake S, Haag A, Hamer HM, Dittmer C, Bien S, Oertel

WH, Rosenow F (2003) Language lateralization in patients with temporal lobe epilepsy: a comparison of functional transcranial Doppler sonography and the Wada-test. Neuroimage Jul;19(3):1228-32.

Rutten GJ, Ramsey NF, van Rijen PC, Alpherts WC, van Veelen CW (2002) FMRI-determined language lateralization in patients with unilateral or mixed language dominance according to the Wada-test. Neuroimage Sep;17(1):447-60.

Door: Rob Rouhl (r.rouhl@mumc.nl), neurologie; Frédéric Schaper, neurologie en neurochirurgie; Linda Ackermans, neurochirurgie; Mariëlle Vlooswijk, neurologie; Vivianne van Kranen-Mastenbroek, klinische neurofysiologie; Louis Wagner en Albert Colon, neurologie; Yasin Temel, neurochirurgie, Maastricht Universitair Medisch Centrum+, Maastricht en Academisch Centrum voor Epileptologie Kempenhaeghe/MUMC+, Heeze/Maastricht

\section{Gevolgen van diepe hersen- stimulatie van de voorste thalamuskern bij epilepsie: focus op bijwerkingen}

Diepe hersenstimulatie is één van de mogelijke behandelingen voor patiënten met medicatie-resistente epilepsie en zorgt bij een aanzienlijk deel van deze patiënten voor vermindering van aanvallen. Er komen echter ook bijwerkingen voor. In deze bijdrage wordt een overzicht gegeven van de bijwerkingen en de betekenis van deze bijwerkingen in de klinische praktijk.

Diepe hersenstimulatie (DBS) wordt sinds $201 \mathrm{I}$ in Nederland toegepast als behandelmethode bij medicatie-resistente epilepsie, vooral bij patiënten bij wie er geen mogelijkheid is om de epileptogene zone neurochirurgisch te verwijderen. Sindsdien zijn er enkele tientallen patiënten behandeld, met doorgaans een gunstig effect op de aanvalsfrequentie (Rouhl et al., 20I4). De toepassing van DBS bij epilepsiepatiënten in Nederland is gebaseerd op de SANTE-studie.

\section{Klinische trial}

De SANTE-studie is het enige dubbelblinde gerandomiseerde klinisch onderzoek naar de effecten en veiligheid van DBS-behandeling bij epilepsie waarvan tot op heden de gegevens van zijn gepubliceerd (Fisher et al., 2010). IIo patiënten met medicatie-resistente epilepsie, met ten minste zes aanvallen per maand, kregen DBS-elektroden geïmplanteerd en na een maand startte óf I) de behande- ling met een vaststaand stimulatieschema of 2) geen stimulatie, waarbij patiënten niet op de hoogte waren van het al dan niet starten van de stimulatie. Na drie maanden (blinde) behandeling was de aanvalsfrequentie in de gestimuleerde groep met 40,4\% gedaald, waar deze in de groep die geen stimulatie kreeg met $14,5 \%$ was afgenomen, een significant verschil. Na deze drie maanden werd de blindering opgeheven en kregen alle patiënten stimulatie. Na vijfentwintig maanden was hierop de aanvalsfrequentie met $56 \%$ gedaald en na vijf jaar tot $69 \%$, waarbij na vijf jaar $68 \%$ van de patiënten een aanvalsreductie van $50 \%$ of meer had. Ondanks deze netto goede resultaten nam bij enkele patiënten de aanvalsfrequentie echter toe in plaats van af (Salanova et al., 2015).

Aan de implantatie van de elektroden, verlengkabel en stimulator zijn mogelijke complicaties verbonden. Zo kreeg in de SANTE-studie I2,7\% van de patiënten een infectie 